$$
\begin{gathered}
\text { Departement für Kleintiere } \\
\text { Klinik für Kleintiermedizin } \\
\text { der Vetsuisse-Fakultät Universität Zürich }
\end{gathered}
$$

Direktorin: Prof. Dr. med. vet. Claudia Reusch, dipl. ECVIM-CA

Arbeit unter Leitung von Dr. med. vet. Peter Kook, dipl. ACVIM \& ECVIM-CA

\title{
Evaluation of esophageal high-resolution manometry in awake and sedated dogs
}

\author{
Inaugural-Dissertation \\ zur Erlangung der Doktorwürde der \\ Vetsuisse-Fakultät Universität Zürich \\ vorgelegt von \\ Jennifer Kempf \\ Tierärztin \\ von Kehl, Deutschland \\ genehmigt auf Antrag von \\ Prof. Dr. Claudia Reusch, dipl. ECVIM-CA, Hauptreferentin
}

Zürich 2013 


$$
\begin{gathered}
\text { Departement für Kleintiere } \\
\text { Klinik für Kleintiermedizin } \\
\text { der Vetsuisse-Fakultät Universität Zürich }
\end{gathered}
$$

Direktorin: Prof. Dr. med. vet. Claudia Reusch, dipl. ECVIM-CA

Arbeit unter Leitung von Dr. med. vet. Peter Kook, dipl. ACVIM \& ECVIM-CA

\title{
Evaluation of esophageal high-resolution manometry in awake and sedated dogs
}

\author{
Inaugural-Dissertation \\ zur Erlangung der Doktorwürde der \\ Vetsuisse-Fakultät Universität Zürich \\ vorgelegt von \\ Jennifer Kempf \\ Tierärztin \\ von Kehl, Deutschland \\ genehmigt auf Antrag von \\ Prof. Dr. Claudia Reusch, dipl. ECVIM-CA, Hauptreferentin
}

Zürich 2013 
Zusammenfassung 3

Summary 4

$\begin{array}{ll}\text { Manuscript } & 5\end{array}$

- Abstract 6-7

- Introduction $\quad 8-9$

- Materials and Methods $\quad$ 10-12

- Results $13-15$

- Discussion $\quad 16-19$

$\begin{array}{lr}\text { - Footnotes } & 20\end{array}$

- References $21-23$

- Figures 1-3 24-26

Acknowledgements 


\section{Zusammenfassung}

Der Ösophagus ist ein aus drei funktionellen Regionen bestehender muskulärer Schlauch mit oberem ösophagealen Sphinkter (OÖS), tubulärem Ösophagus und unterem ösophagealen Sphinkter (OÖS). Die hochauflösende Manometrie (HRM) ist der Goldstandard in der ösophagealen Funktionsdiagnostik beim Menschen. Ziele dieser Studie waren (1) die Durchführbarkeit von HRM bei Hunden, (2) Parameter für die Ösophagusfunktion, und (3) den Einfluss einer Sedation auf die Messdaten zu evaluieren.

Ein Katheter mit 36 Drucksensoren wurde intranasal eingeführt und Schlücke mit Flüssigkeiten und Futter durchgeführt. Die Messungen wurden 30 Minuten nach Sedation mit Buprenorphin und Acepromazin wiederholt. Bei 14/22 Hunden konnte die HRM durchgeführt werden. Den OÖS charakterisierende Parameter waren: Ruhedruck, Residualdruck, Relaxationszeit bis zum Nadir und Relaxationsdauer; tubulärer Ösophagus: peristaltisches kontraktiles Integral, Bolustransportzeit und kontraktile Peristaltikgeschwindigkeit; UÖS: Ruhedruck und Residualdruck. Medianwerte (wach vs sediert) wurden für Flüssigkeits- und Futterschlücke berechnet. Signifikante Unterschiede wurden für den OÖS Residualdruck, Relaxationszeit bis zum Nadir, Bolustransportzeit und kontraktile Peristaltikgeschwindigkeit gefunden. Zusammengefasst ist die HRM bei wachen Hunden zur Evaluation der Ösophagusfunktion durchführbar. Da die Sedation nur einzelne Parameter minimal beeinflusst, ist es möglich den Schluckakt bei unkooperativen Patienten auch unter Sedation zu beurteilen.

Stichworte: Hochauflösende Manometrie, Ösophagusfunktion, Sedation 


\section{Summary}

The esophagus is a muscular tube consisting of three functional regions: the upper esophageal sphincter (UES), the tubular esophagus and the lower esophageal sphincter (LES). Esophageal high-resolution manometry (HRM) is regarded the gold standard for evaluating esophageal motor function in humans. Goals of the study were (1) to evaluate feasibility of HRM in dogs,

(2) to generate parameters for assessing esophageal function, and (3) to determine effects of a sedation on manometric data.

A HRM catheter with 36 pressure sensors was inserted intranasally and swallows of liquids and solid food were performed. Measurements were repeated 30 minutes after administration of buprenorphine and acepromazine. HRM was successfully performed in 14/22 dogs. Parameters for assessing the UES were: baseline pressure, residual pressure, relaxation time to nadir, and relaxation duration. For the tubular portion of the esophagus: peristaltic contractile integral, bolus transit time, and contractile front velocity and for the LES: baseline and residual pressure. Median values of parameters (awake vs sedated) were determined for liquid and solid swallows. Significant differences were found for the UES residual pressure, relaxation time to nadir, bolus transit time, and contractile front velocity.

In conclusion, HRM is feasible for evaluating esophageal function in awake dogs. While sedation in uncooperative patients may minimally influence results of single parameters, an overall assessment of the complete swallowing act appears possible.

Keywords: High-resolution manometry, esophageal function, sedation 
Evaluation of esophageal high-resolution manometry in awake and sedated dogs

Jennifer Kempf, Mag med vet; Henriette Heinrich, Dr med; Claudia E. Reusch, Prof Dr med vet; Peter H. Kook, Dr med vet

From the Clinic for Small Animal Internal Medicine, Vetsuisse Faculty, University of Zurich, 8057 Zurich, Switzerland (Kempf, Reusch, Kook); and the Gastrointestinal Function Laboratory, University Hospital Zurich, 8006 Zurich, Switzerland (Henriette Heinrich).

Presented as an oral presentation at the 22th European College of Veterinary Internal Medicine congress, Maastricht, Netherlands, September 2012.

Address correspondence to Peter Hendrik Kook at peterhendrikkook@gmail.com. 


\begin{abstract}
Objective- To evaluate the use of high-resolution manometry (HRM) in awake and sedated dogs and to assess potential effects of a standard sedation protocol.
\end{abstract}

Animals-22 Beagles.

Procedures-A HRM catheter with 36 pressure sensors was inserted intranasally in each dog. After an adaption period of 5 minutes, each set of measurements included 5 swallows of a liquid and 5 swallows of a solid bolus. Measurements were repeated 30 minutes after IM administration of buprenorphine and acepromazine.

Results-HRM was successfully performed in 14 dogs. Data sets of 8 dogs were adequate for analysis. For the upper esophageal sphincter, median values of baseline pressure, residual pressure, relaxation time to nadir, and relaxation duration were determined for awake and sedated dogs for liquid and solid swallows. For the tubular portion of the esophagus, median values of peristaltic contractile integral, bolus transit time, and contractile front velocity were determined for awake and sedated dogs for liquid and solid swallows. For the lower esophageal sphincter, median values of baseline pressure and residual pressure were determined for awake and sedated dogs for liquid and solid swallows. Significant differences (awake vs sedated) were found for the upper esophageal sphincter residual pressure (liquid swallows), relaxation time to nadir (liquid swallows), bolus transit time (solid swallows), and contractile front velocity (solid swallows).

Conclusions and Clinical Relevance-HRM was feasible for evaluation of esophageal function in most awake dogs. Although sedation in uncooperative patients may minimally influence results of some variables, an overall assessment of swallowing should be possible. 


\section{Abbreviations}

BTT Bolus transit time

CFV Contractile front velocity

HRM High-resolution manometry

LES Lower esophageal sphincter

PCI Peristaltic contractile integral

UES Upper esophageal sphincter 


\section{Introduction}

The esophagus is a hollow muscular tube that consists of 3 functional regions: the UES, the tubular portion of the esophagus, and the LES. Its primary function is to transport liquids or food to the stomach and to prevent retrograde movement of gastric contents. Manometry allows the depiction of pressure profiles generated by esophageal peristalsis and provides clinically relevant information on esophageal motor function. Conventional manometry involves the use of catheters with a few widely spaced channels that are continuously perfused with water. Differences in the resistance to water flow among the manometric channels are measured by pressure sensors and then converted to an electrical signal, and recordings are interpreted as line tracings. Because of the small number of channels and the wide gaps between those channels, a time-consuming pull-through technique is needed. Use of an increased number of pressure sensors on the catheter and creation of spatiotemporal contour plots for data display have provided a new technique: HRM. This technique was first described in 1998. ${ }^{1}$ Since then, HRM has become the criterion-referenced standard for the evaluation of esophageal function in humans. Most importantly the dynamic interaction of the UES, tubular portion of the esophagus, and LES during swallowing can be evaluated concurrently, which facilitates detection of disorders in this complex functional system. Furthermore, because of the closely spaced pressure sensors, there is no loss of information, even for subtle functional abnormalities limited to a short segment of the esophagus. ${ }^{2}$ Moreover, displacements of the high pressure zone (esophagogastric junction, including the LES) from the recording channel during breathing-related movements as well as a decrease in esophageal length during swallowing cannot be misinterpreted as LES relaxation (so-called

pseudorelaxation). ${ }^{3}$ Also, pattern recognition of the colored contour plot facilitates diagnosis, ${ }^{4}$ and the soft catheter material improves patient comfort during the procedure. In veterinary medicine, conventional manometry has rarely been used in companion animals and has not 
gained wide acceptance as a diagnostic tool. ${ }^{5,6}$ In clinical practice, fluoroscopic evaluations of swallowing are most commonly used for the assessment of esophageal disorders and to provide information on effectiveness of bolus transport and esophageal clearance. Neither fluoroscopy nor HRM allows determination of the underlying cause of dysfunction, but HRM provides the possibility of pressure measurements, which therefore can be used to directly assess esophageal function. ${ }^{7,8}$ To the authors' knowledge, HRM has not been performed in dogs. The primary objective of the study reported here was to evaluate HRM as a diagnostic tool for esophageal functional disorders in dogs. Second, because intranasal insertion of a catheter was expected to be problematic in uncooperative patients, we also intended to assess potential effects of sedation on manometric data. 


\section{Materials and Methods}

Animals - Twenty-two healthy Beagles (12 females and 10 males with a median age of 2 years, median body weight of $12.85 \mathrm{~kg}$, and median body condition score of 5 [scale of 1 to 9]) were included in the study. The study was approved by the Cantonal Veterinary Office of Zurich and conducted in accordance with guidelines established by the Animal Welfare Act of Switzerland (permission No. 185/2011).

HRM-A solid-state catheter ${ }^{\mathrm{a}}$ (outer diameter, $2.75 \mathrm{~mm}$ ) with 36 circumferential pressure sensors spaced at intervals of $10 \mathrm{~mm}$ was used for HRM (Figure 1). Each circumferential sensor consisted of 16 radially dispersed pressure-sensitive segments, and the pressure of the sensor was the mean for the 16 segments. The catheter was calibrated via externally applied pressure in a calibration chamber prior to each procedure; calibration pressures were applied from 0 to $300 \mathrm{~mm} \mathrm{Hg}$ and then from $300 \mathrm{~mm} \mathrm{Hg}$ back to $0 \mathrm{~mm} \mathrm{Hg}$. Catheters were maintained in accordance with guidelines provided by the manufacturer. Use of the catheter enabled creation of spatiotemporal contour plots for HRM data display (Figure 2).

Data collection-All HRM examinations were performed with the dogs in a sitting position. The HRM catheter was lubricated with a $2 \%$ lidocaine gel, passed intranasally, and positioned to record the entire esophagus from the pharynx to the stomach. Real-time pressure monitoring was used to ensure accurate catheter placement. Three or 4 pressure sensors were positioned intragastrically to enable measurement of gastric reference pressure and to rule out artifacts of the esophagogastric junction caused by breathing-related movements. The inserted catheter was manually held in position throughout each examination. Measurements were initially obtained in awake dogs. Dogs were then sedated by IM administration of buprenorphine $(0.007 \mathrm{mg} / \mathrm{kg})$ and acepromazine maleate $(0.03 \mathrm{mg} / \mathrm{kg})$. Thirty minutes after administration of the drugs, measurements were obtained again. The HRM procedure included a 5-minute adaptation period, baseline assessment of sphincter pressures, 5 swallows 
of a liquid, and 5 swallows of a solid bolus. Liquid consisted of 3 to $5 \mathrm{~mL}$ of water or flavored water; the volume was dependent on the willingness of a dog to swallow without coughing. The liquid was placed into the oral cavity with a syringe that was inserted through the gap between the premolar and molar teeth. The solid bolus was a commercially available canned food $^{\mathrm{b}}$ formed into a meat ball $(3 \mathrm{~cm}$ in diameter); each dog was allowed to take the meat ball from the examiner's hand. All swallows (liquid and solid bolus) were performed at 30-second intervals. Additional swallows were recorded if the planned swallows appeared to be technically inadequate. Swallows following too soon after a previous swallow (within a 30second interval), failed contractions, swallows interrupted by coughing or affected by reverse sneezing, or catheter movement were considered to yield technically inadequate data and were excluded from analysis.

Data analysis-Variables for analysis were chosen in accordance with evaluation criteria used in human medicine. ${ }^{9,10}$ Characterization of the UES comprised a pressure measurement of the resting sphincter (baseline pressure) as well as relaxation variables. The latter were the UES residual pressure, relaxation time to nadir, relaxation duration, and recovery time. The residual pressure was defined as the nadir of the UES pressure during swallowing-induced relaxation. Relaxation time to nadir was defined as the interval from onset of the UES relaxation until the nadir pressure was reached. Relaxation duration was defined as the interval from the beginning to the end of UES relaxation. Characterization of the tubular portion of the esophagus comprised the PCI, BTT, and CFV. The PCI represented the strength of a peristaltic wave and was calculated by outlining a space-time box that encompassed the entire peristaltic wave; the mean pressure was then multiplied by the length and by the duration of the peristaltic wave. The BTT was defined as the time from the onset of swallowing- induced UES relaxation until the bolus arrived at the LES. The CFV was measured by determining the bestfit tangent along the peristaltic wave. Characterization of the 
LES comprised a pressure measurement of the resting sphincter (baseline pressure) and the residual pressure during relaxation. The LES residual pressure was defined as the lowest 3second mean LES pressure relative to intragastric pressure during swallowing-induced relaxation. Manometric data for all 3 variables were analyzed by use of computer software. ${ }^{\mathrm{c}}$ First, the data were corrected for thermal compensation because of the thermal sensitivity of the pressure sensors. This was accomplished by identifying the moment at which the catheter was removed from the nose of a dog at the end of each recording. At that time, the catheter was still at body temperature and all pressure sensors were exposed to atmospheric pressure and ambient temperature. The software automatically set that pressure at a value of 0 and applied thermal correction to all the recorded data for that dog. All values were calculated by use of the mean value for each dog.

Statistical analysis - Data of the dogs when awake and sedated were compared via the Wilcoxon signed rank test with commercial software. ${ }^{\mathrm{d}}$ Significance was set at values of $\mathrm{P}<$ 0.05 . 


\section{Results}

HRM procedure-The HRM measurements were successfully obtained in 14 of $22(63.6 \%)$ awake dogs (Figure 3). For the 8 dogs in which HRM measurements could not be obtained, 5 had strong defense reactions that precluded intranasal insertion of the catheter. In 2 other dogs, intranasal passage of the catheter was impeded after the catheter had been inserted into the ventral meatus to a depth of 5 to $7 \mathrm{~cm}$. In $1 \mathrm{dog}$, the catheter was placed accurately, but measurements had to be stopped because of reverse sneezing of the dog. Only dogs for which we were able to obtain manometric values during the awake state were sedated for HRM measurements in the sedated state. Median duration of HRM measurements was 28.5 minutes (range, 23 to 42 minutes) for the 14 dogs when awake and 19.5 minutes (range, 17 to 46 minutes) for those dogs when sedated. Technically adequate swallows were successfully acquired for swallows of liquid (median of 4 and 3 for the awake and sedated states, respectively) and a solid bolus (median of 4 and 5 for the awake and sedated states, respectively) for each dog.

HRM data-Data for 6 of 14 dogs were excluded from analysis because of technical issues (eg, pressure artifacts or defective pressure sensors). Thus, data for 8 dogs with complete, technically adequate data for both the awake and sedated states were included. Median and range values for swallows of a liquid and solid bolus in awake and sedated dogs were calculated.

UES-Median UES baseline pressure was $14.2 \mathrm{~mm} \mathrm{Hg}$ (range, 8.6 to $27.5 \mathrm{~mm} \mathrm{Hg}$ ) in awake dogs and $15.7 \mathrm{~mm} \mathrm{Hg}$ (range, 6.9 to $79.7 \mathrm{~mm} \mathrm{Hg}$ ) in sedated dogs. Median UES residual pressure in awake dogs was $-3.6 \mathrm{~mm} \mathrm{Hg}$ (range, -10.5 to $0.3 \mathrm{~mm} \mathrm{Hg}$ ) for swallow of a liquid and $2.3 \mathrm{~mm} \mathrm{Hg}$ (range, -4.8 to $12.4 \mathrm{~mm} \mathrm{Hg}$ ) for swallow of a solid bolus. Median UES residual pressure in sedated dogs was $-0.8 \mathrm{~mm} \mathrm{Hg}$ (range, -6.0 to $9.6 \mathrm{~mm} \mathrm{Hg}$ ) for swallow of a liquid and $5.1 \mathrm{~mm} \mathrm{Hg}$ (range, -8.3 to $17.9 \mathrm{~mm} \mathrm{Hg}$ ) for swallow of a solid bolus. Median 
UES relaxation time to nadir in awake dogs was 72 milliseconds (range, 58 to 140

milliseconds) for swallow of a liquid and 106 milliseconds (range, 85 to 210 milliseconds) for swallow of a solid bolus. Median UES relaxation time to nadir in sedated dogs was 105 milliseconds (range, 74 to 190 milliseconds) for swallow of a liquid and 144 milliseconds (range, 60 to 194 milliseconds) for swallow of a solid bolus. Median UES relaxation duration in awake dogs was 196 milliseconds (range, 145 to 305 milliseconds) for swallow of a liquid and 259 milliseconds (range, 154 to 623 milliseconds) for swallow of a solid bolus. Median UES relaxation duration in sedated dogs was 238 milliseconds (range, 163 to 360 milliseconds) for swallow of a liquid and 339 milliseconds (range, 260 to 388 milliseconds) for swallow of a solid bolus. Median UES recovery time in awake dogs was 120 milliseconds (range, 65 to 235 milliseconds) for swallow of a liquid and 170 milliseconds (range, 60 to 413 milliseconds) for swallow of a solid bolus. Median UES recovery time in sedated dogs was 135 milliseconds (range, 87 to 170 milliseconds) for swallow of a liquid and 205 milliseconds (range, 144 to 256 milliseconds) for swallow of a solid bolus. Significant differences between the awake and sedated states were found during swallowing of a liquid for the UES residual pressure $(\mathrm{P}=0.031)$ and UES relaxation time to nadir $(\mathrm{P}=0.047)$.

Tubular portion of the esophagus-Median PCI in awake dogs was $525 \mathrm{~mm} \mathrm{Hg \bullet s} \bullet \mathrm{cm}$ (range, 293 to $1,274 \mathrm{~mm} \mathrm{Hg} \bullet \mathrm{s}^{\bullet} \mathrm{cm}$ ) for swallow of a liquid and 1,136 $\mathrm{mm} \mathrm{Hg \bullet} \bullet \bullet \mathrm{cm}$ (range, 604 to $2,186 \mathrm{~mm} \mathrm{Hg} \bullet \mathrm{s}^{\bullet} \mathrm{cm}$ ) for swallow of a solid bolus. Median PCI in sedated dogs was 481 $\mathrm{mm} \mathrm{Hg} \bullet \mathrm{s}^{\bullet} \mathrm{cm}$ (range, 38 to $955 \mathrm{~mm} \mathrm{Hg} \bullet \mathrm{s}^{\bullet} \mathrm{cm}$ ) for swallow of a liquid and 1,555 $\mathrm{mm} \mathrm{Hg} \bullet \bullet \bullet \mathrm{cm}$ (391 to 2,731 $\mathrm{mm} \mathrm{Hg} \bullet \mathrm{s}^{\bullet} \mathrm{cm}$ ) for swallow of a solid bolus. Median BTT in awake dogs was 3.9 seconds (range, 2.7 to 5.4 seconds) for swallow of a liquid and 4.1 seconds (range, 3.5 to 5.7 seconds) for swallow of a solid bolus. Median BTT in sedated dogs was 4.7 seconds (range, 3.3 to 5.6 seconds) for swallow of a liquid and 5.8 seconds (range, 4.5 to 9.7 seconds) for swallow of a solid bolus. Median CFV in awake dogs was $6.6 \mathrm{~cm} / \mathrm{s}$ (range, 4.7 to $9.0 \mathrm{~cm} / \mathrm{s}$ ) 
for swallow of a liquid and $6.1 \mathrm{~cm} / \mathrm{s}$ (range, 3.9 to $7.3 \mathrm{~cm} / \mathrm{s}$ ) for swallow of a solid bolus.

Median CFV in sedated dogs was $5.6 \mathrm{~cm} / \mathrm{s}$ (range, 4.4 to $8.0 \mathrm{~cm} / \mathrm{s}$ ) for swallow of a liquid and $5.0 \mathrm{~cm} / \mathrm{s}$ (range, 2.9 to $5.9 \mathrm{~cm} / \mathrm{s}$ ) for swallow of a solid bolus. Significant differences between the awake and sedated states were found during swallowing of a solid bolus for the BTT $(\mathrm{P}=$ $0.014)$ and $\mathrm{CFV}(\mathrm{P}=0.014)$.

LES-Median LES baseline pressure was $36.9 \mathrm{~mm} \mathrm{Hg}$ (range, 14.6 to $45.1 \mathrm{~mm} \mathrm{Hg}$ ) in awake dogs and $23.0 \mathrm{~mm} \mathrm{Hg}$ (range, 6.0 to $39.4 \mathrm{~mm} \mathrm{Hg}$ ) in sedated dogs. Median LES residual pressure in awake dogs was $11.2 \mathrm{~mm} \mathrm{Hg}$ (range, 1.9 to $19.1 \mathrm{~mm} \mathrm{Hg}$ ) for swallow of a liquid and $5.6 \mathrm{~mm} \mathrm{Hg}$ (range, 0 to $11.5 \mathrm{~mm} \mathrm{Hg}$ ) for swallow of a solid bolus. Median LES residual pressure in sedated dogs was $12.6 \mathrm{~mm} \mathrm{Hg}$ (range, 6.7 to $31.5 \mathrm{~mm} \mathrm{Hg}$ ) for swallow of a liquid and $7.2 \mathrm{~mm} \mathrm{Hg}$ (range, 0.2 to $22.2 \mathrm{~mm} \mathrm{Hg}$ ) for swallow of a solid bolus. 


\section{Discussion}

To our knowledge, the study reported here represents the first description of HRM performed in dogs and thus the first description of the HRM assessment of esophageal motility in this species. Currently, the only manometric data available for dogs have been generated via conventional manometry. In 1 study, ${ }^{6} 12$ healthy dogs of various ages and breeds had a mean LES resting pressure of $22.3 \mathrm{~mm} \mathrm{Hg}$ (range, 15 to $37 \mathrm{~mm} \mathrm{Hg}$ ). Those measurements were obtained with a water-perfused catheter that contained only 2 or 3 channels, and those LES values are lower than the values for the present study. This difference is most likely attributable to downward movement of the LES during inspiration, which thus results in loss of contact with the recording channel. In another study, ${ }^{11} 16$ healthy mixed-breed dogs were examined by use of a catheter fitted with a Dent sleeve, and LES resting pressure was 38.5 $\mathrm{mm} \mathrm{Hg}$, which compares well with the $36.9 \mathrm{~mm} \mathrm{Hg}$ detected in the present study. The similar LES residual pressure obtained via conventional manometry with a Dent sleeve is not surprising because the sleeve was long enough to span the range of sphincter movement in a resting condition. No data (eg, BTT, PCI, and CFV) are currently available for evaluation of the dynamic action of the esophagus.

In humans, reference values for HRM analysis have been generated with patients in the supine position. The standard HRM swallowing protocol in humans comprises a series of 10 swallows of water ( $5 \mathrm{~mL}$ of water/ swallow). ${ }^{9}$ The supine position and the small volume of each swallow do not represent typical human eating behavior and the physiologic challenge of drinking and eating during a daily routine. In a recent study ${ }^{12}$ in humans, reference values for swallow of a liquid and solid $\left(1 \mathrm{~cm}^{3}\right.$ of bread) with patients in upright and supine positions revealed that body position affects esophageal motility and, therefore, can be used to provoke esophageal symptoms. The vigor of esophageal contractions becomes weaker for patients in a sitting position because gravity assists transport of the bolus. ${ }^{13-15}$ Furthermore, abnormalities 
such as hypertensive contractility, esophageal spasm, achalasia, and increased resistance to flow at the esophagogastric junction would be missed if swallowing of only water were used. ${ }^{\mathrm{e}}$ Thus, we chose to include swallowing of both liquid and a solid bolus in the swallowing protocol, and all HRM procedures were performed with the dogs in a sitting position. It could be argued that this is also not a typical anatomic position for eating behavior of dogs because dogs typically eat while standing with the head and neck positioned down toward the food. However, considering that all liquid volumes were administered via syringe, imitating a physiologic position would have led to stressful situations with hindered swallowing or even refusal to swallow. In the present study, the dogs did not spontaneously drink water from a bowl, probably because of the unnatural state with the intranasal catheter. To avoid an influence of psychological stress on sphincter pressures, ${ }^{16,17}$ a sitting position was chosen. In humans, it is feasible to use standardized volumes for each swallow. Patients typically are instructed to hold the liquid bolus in the oral cavity until the examiner gives the command to swallow it as a single bolus. This approach is not feasible in dogs; consequently, the actual volume of each swallow inevitably differed. However, varying the volume of liquid between 1 and $20 \mathrm{~mL}$ has little or no effect on esophageal peristalsis in humans because these small amounts do not distend the esophageal lumen. ${ }^{18}$ However, variation in volumes ( 3 to $5 \mathrm{~mL}$ ) may have had some undetectable effect on esophageal peristalsis in dogs. By incorporating swallowing of a solid bolus into the present study protocol, the triggering of esophageal muscle contractions in response to a larger volume and a bolus of a different consistency (liquid vs solid) could be assessed. Therefore, functional disorders would not be missed because of swallowing small volumes of liquid.

All HRM examinations in the present study were performed with small-diameter catheters designed for use in humans. The small-diameter version was chosen to provide the most comfort for the dogs. However, handling of these catheters was laden with problems because 
multiple technical issues (eg, pressure artifacts or defective pressure sensors) were encountered, which led to retrospective exclusion of some fully completed recordings. Analysis of the results suggested that at the current technical level, use of these smalldiameter catheters is impractical in dogs. Experiments currently are being conducted to evaluate a more robust solidstate catheter specially designed for HRM examination in dogs.

The objective of the present study was to evaluate the feasibility of conducting HRM in awake and sedated dogs. For sedation, acepromazine in combination with an opioid was chosen because it guaranteed the required degree of sedation for insertion of the catheter. Also, this combination did not adversely affect swallowing in sedated dogs and avoided aspiration of material into the trachea. A successful manometric examination could only be achieved in 14 of 22 dogs. It is likely that improvement in handling skills (ie, a learning curve of the operator) would increase the proportion of dogs that can be successfully evaluated via HRM.

Significant differences were detected between the awake and sedated states during swallowing of a liquid for the UES residual pressure and the UES relaxation time to nadir. Both variables are highly dependent on the intrabolus pressure (pressure generated within the bolus by muscular contraction) of the swallowed contents during UES relaxation. The UES values generated in this study were a combination of minimal residual pressure and intrabolus pressure. Thus, to exclusively assess the nadir pressure without interfering with the swallowed content, data for swallowing of a dry bolus with little saliva should be obtained and analyzed. High intrabolus pressures are indicative of flow obstruction ${ }^{19,20}$; thus, it would be clinically relevant to determine reference values of intrabolus pressures for swallowing of all types of contents, not just a dry bolus with little saliva. In human medicine, deglutitive UES relaxation variables exist for the assessment of minimal relaxation pressure and intrabolus pressure. ${ }^{21}$ It 
is not yet clear whether there is a clinical need for a separate evaluation of the relaxation pressure and intrabolus pressure in veterinary medicine.

We also detected significant differences between the awake and sedated states during swallowing of a solid bolus for the BTT and CFV. The relevance of BTT and CFV as functional variables currently is debatable. A prolonged BTT should alert an examiner that there might be a defect in one or more functional areas of the esophagus. A closer look at the contour plot will enable examiners to quickly identify the affected part of the esophagus. Bolus transport in the present study was assessed indirectly via pressure topography. Ideally, visualization of the swallowed liquid or solid bolus would be achieved via HRM combined with impedance measurement to definitely assess the actual bolus transit. ${ }^{22}$ The CFV was included as a variable because it is used for detection of esophageal spasm in humans. ${ }^{10}$ Esophageal spasm has been reported only once in veterinary medicine, ${ }^{23}$ and it has yet to be determined whether CFV will be a valuable tool to characterize this condition.

A limitation of the present study was the small number of dogs evaluated. Therefore, significant differences for HRM variables should be interpreted cautiously. At this time, the clinical relevance of the observed differences is unclear. It also is not clear whether sedation would also affect HRM analysis in dogs with esophageal motility disorders, although we believe that sedation would be likely to affect that analysis. Therefore, the primary goal should always be to examine esophageal function of a patient in an awake state, and sedation should be reserved for uncooperative dogs.

We conclude that HRM is a feasible technique for use in awake dogs, and an overall assessment of swallowing is possible in sedated dogs. Reference values from a large population of dogs of various breeds and ages should be established. 


\section{Footnotes}

a. ManoScan ESO catheter, small diameter regular (EAS), Sierra Scientific Instruments, Los Angeles, Calif.

b. Sensitivity Control, Royal Canin, Dällikon, Switzerland.

c. Smart Mouse, ManoView ESO analysis software, Sierra Scientific Instruments, Los Angeles, Calif.

d. GraphPad Prism, version 5.0, GraphPad Software Inc, San Diego, Calif.

e. Sweis R, Anggiansah A, Wong T, et al. T1889 inclusion of solid swallows and a test meal increase the clinical utility of high resolution manometry in patients with dysphagia (abstr). Gastroenterology 2010;138:S600. 


\section{References}

1. Clouse RE, Staiano A, Alrakawi A. Development of a topographic analysis system for manometric studies in the gastrointestinal tract. Gastrointest Endosc 1998;48:395-401.

2. Fox M, Hebbard G, Janiak P, et al. High-resolution manometry predicts the success of oesophageal bolus transport and identifies clinically important abnormalities not detected by conventional manometry. Neurogastroenterol Motil 2004;16:533-542.

3. Clouse RE, Staiano A, Alrakawi A, et al. Application of topographical methods to clinical esophageal manometry. Am J Gastroenterol 2000;95:2720-2730.

4. Soudagar AS, Sayuk GS, Gyawali CP. Learners favour high resolution oesophageal manometry with better diagnostic accuracy over conventional line tracings. Gut 2012;61:798803.

5. Diamant N, Szczepanski M, Mui H. Idiopathic megaesophagus in the dog: reasons for spontaneous improvement and a possible method of medical therapy. Can Vet J 1974;15:6671.

6. Rogers WA, Fenner WR, Sherding RG. Electromyographic and esophagomanometric findings in clinically normal dogs and in dogs with idiopathic megaesophagus. J Am Vet Med Assoc 1979;174:181-183.

7. Pouderoux P, Shi G, Tatum RP, et al. Esophageal solid bolus transit: studies using concurrent videofluoroscopy and manometry. Am J Gastroenterol 1999;94:1457-1463.

8. Davies HA, Evans KT, Butler F, et al. Diagnostic value of "breadbarium" swallow in patients with esophageal symptoms. Dig Dis Sci 1983;28:1094-1100. 
9. Ghosh SK, Pandolfino JE, Zhang Q, et al. Quantifying esophageal peristalsis with highresolution manometry: a study of 75 asymptomatic volunteers. Am J Physiol Gastrointest Liver Physiol 2006;290:G988-G997.

10. Pandolfino JE, Gosh SK, Rice J, et al. Classifying esophageal motility by pressure topography characteristics: a study of 400 patients and 75 controls. Am J Gastroenterol 2008; 103:27-37.

11. Strombeck DR, Harrold D. Effect of gastrin, histamine, serotonin, and adrenergic amines on gastroesophageal sphincter pressure in the dog. Am J Vet Res 1985;46:1684-1690.

12. Sweis R, Anggiansah A, Wong T, et al. Normative values and inter-observer agreement for liquid and solid bolus swallows in upright and supine positions as assessed by esophageal highresolution manometry. Neurogastroenterol Motil 2011;23:509-517.

13. Roman S, Damon H, Pellissier PE, et al. Does body position modify the results of oesophageal high resolution manometry? Neurogastroenterol Motil 2010;22:271-275.

14. Xiao Y, Read A, Nicodème F, et al. The effect of a sitting vs supine posture on normative esophageal pressure topography metrics and Chicago classification diagnosis of esophageal motility disorders. Neurogastroenterol Motil 2012;24:e509-e516.

15. Xiao Y, Nicodème F, Kahrilas PJ, et al. Optimizing the swallow protocol of clinical highresolution esophageal manometry studies. Neurogastroenterol Motil 2012;24:e489-e496.

16. Cook IJ, Dent J, Shannon S, et al. Measurement of upper esophageal sphincter pressureeffect of acute emotional stress. Gastroenterology 1987;93:526-532.

17. Mittal RK, Stewart WR, Ramahi M, et al. The effects of psychological stress on the esophagogastric junction pressure and swallow-induced relaxation. Gastroenterology 1994;106:1477-1484. 
18. Srinivasan R, Vela MF, Katz PO, et al. Esophageal function testing using multichannel intraluminal impedance. Am J Physiol Gastrointest Liver Physiol 2011;280:G457-G462.

19. Pal A, Williams RB, Cook IJ, et al. Intrabolus pressure gradient identifies pathological constriction in the upper esophageal sphincter during flow. Am J Physiol Gastrointest Liver Physiol 2003;285:G1037-G1048.

20. Scherer JR, Kwiatek MA, Soper NJ, et al. Functional esophagogastric junction obstruction with intact peristalsis: a heterogeneous syndrome sometimes akin to achalasia. J Gastrointest Surg 2009;13:2219-2225.

21. Ghosh SK, Pandolfino JE, Zhang Q, et al. Deglutitive upper esophageal sphincter relaxation: a study of 75 volunteer subjects using solid-state high-resolution manometry. Am J Physiol Gastrointest Liver Physiol 2006;291:525-531.

22. Bredenoord AJ, Smout J. Esophageal motility testing: impedance-based transit measurement and high-resolution manometry. Gastroenterol Clin North Am 2008;37:775791.

23. Gibbon KJ, Trepanier LA, Delaney FA. Phenobarbital-responsive ptyalism, dysphagia, and apparent esophageal spasm in a German Shepherd puppy. J Am Anim Hosp Assoc 2004;40:230-237. 


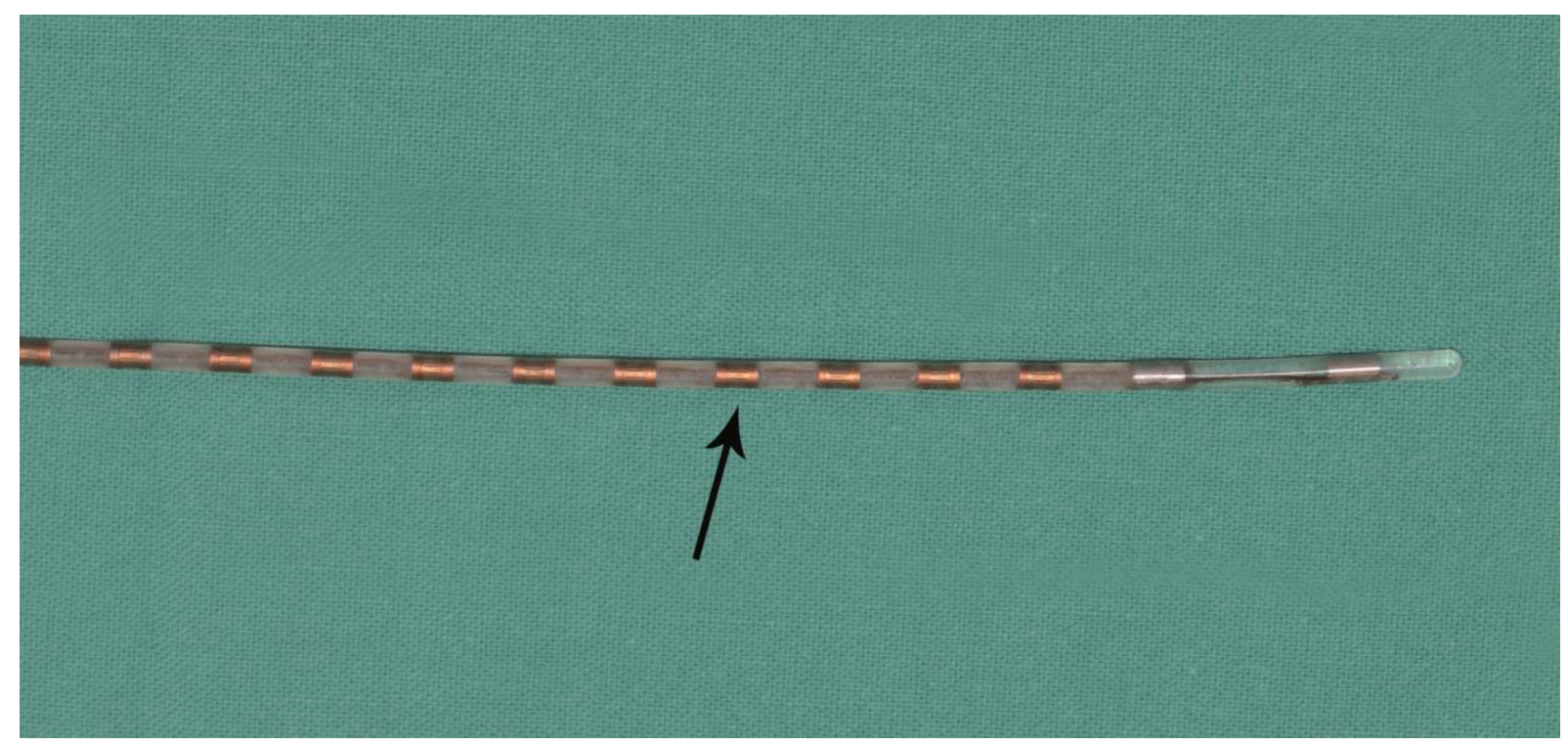

Figure 1-Photograph of the tip of a catheter (outer diameter, $2.75 \mathrm{~mm}$ ) used for HRM in healthy dogs. The catheter contains 36 circumferential solid-state pressure sensors (arrow) spaced at intervals of $10 \mathrm{~mm}$. Each sensor detects pressure from 16 sectors around its circumference. 

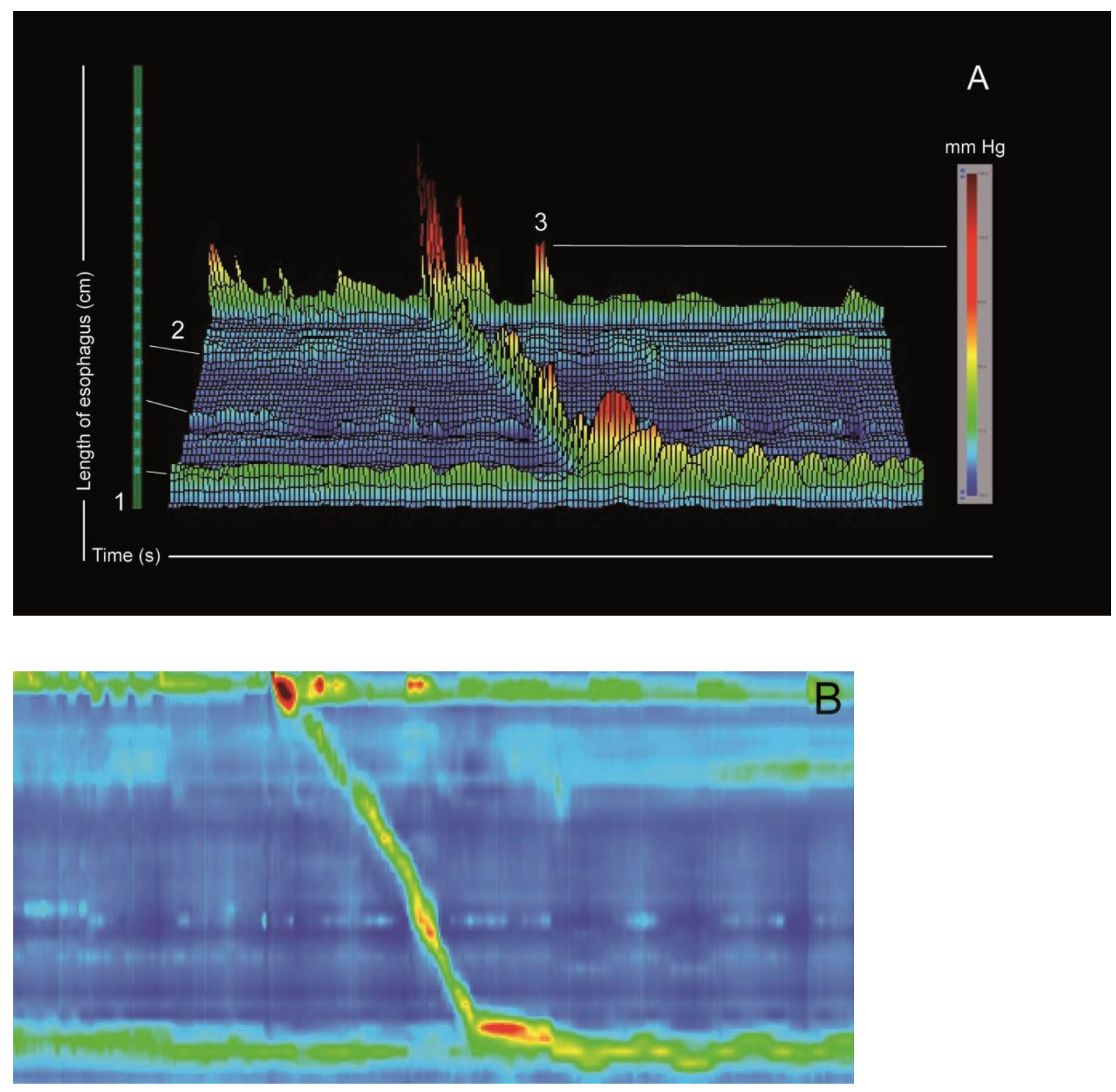

Figure 2-A spatiotemporal contour plot for a dog that was obtained via HRM (A). The closely spaced pressure sensors on the esophageal manometry catheter (1) generate multiple pressure recordings, which correspond to pressure recordings from individual sensors as indicated by the lines between the catheter and the plot (2). Computer software provides color codes for the amplitudes of pressure intensity (3). The final result is a topographic contour plot representing the esophageal pressure profile (B). 


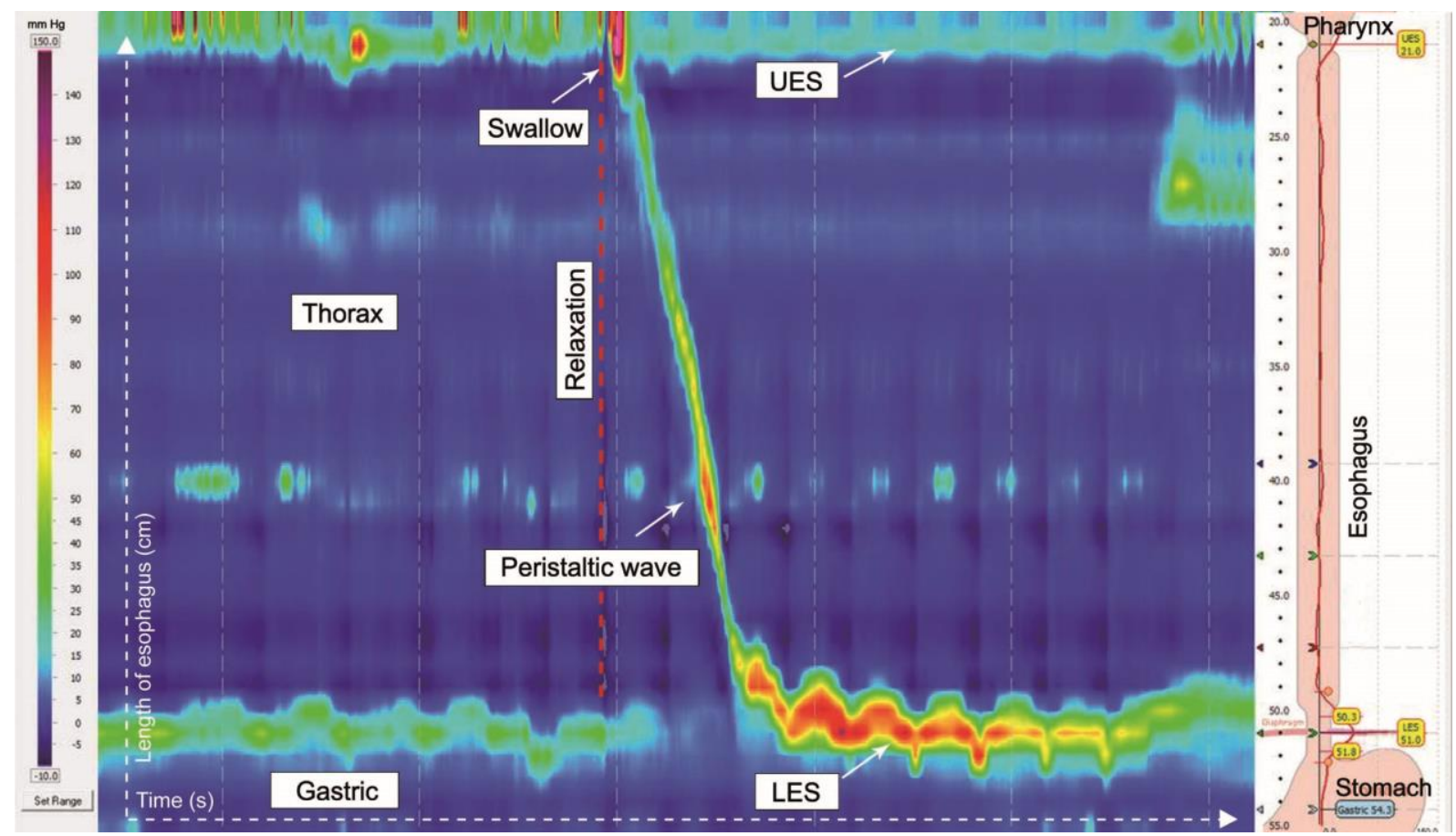

Figure 3-Pressure topography plot of HRM data for a representative healthy Beagle. The plot represents pressures in the esophagus from the pharynx to stomach. Examination was performed with a 36-channel circumferential solid-state probe with pressure sensors at $10-\mathrm{mm}$ intervals. The color scale is on the left and reflects the intensity ( $\mathrm{mm} \mathrm{Hg}$ ) of the pressures (red $=$ high pressure; blue $=$ low pressure). The UES and LES are clearly evident as zones of high pressure. Notice that there is relaxation of both sphincters following a swallow. The schematic on the right side depicts the location of the catheter in the body. 


\section{Acknowledgements}

An dieser Stelle möchte ich mich bei allen bedanken, die zum Gelingen dieser Arbeit beigetragen haben:

Mein Dank gilt Frau Prof. Dr. Claudia Reusch, die mir das Ausführen dieser

Dissertationsarbeit erst ermöglich hat. Ein grosses Dankeschön möchte ich an Herrn Dr. Peter Kook richten, für seinen unermüdlichen Einsatz und sein ausserordentliches Engagement; danke für die gute Zusammenarbeit!

Ein herzliches Dankeschön an Henriette Heinrich für die praktische Einführung in das beschriebene Manometriegerät.

Vielen Dank an Andrea Danninger, die mir bei der Betreuung der Hunde stets eine grosse Hilfe war.

Ein grosses Dankeschön an Nadine Haser, die mir zu jeder Zeit bei der Anfertigung der Bilder und Grafiken behilflich war.

Bei meiner Familie möchte ich mich für die Ermöglichung der langen Ausbildung bedanken. Sie haben mich immer unterstützt und mir ein schönes Zuhause als Rückzugsort und Entspannung geboten.

Danke an meinen Partner, Roger Melliger, für seine liebevolle Unterstützung und ein stets offenes Ohr für Diskussionen jeglicher Art. 


\section{Curriculum Vitae}

Name Jennifer Kempf

Geburtsdatum 13.05.1985

Geburtsort Kehl

Nationalität Deutschland

Heimatort Offenburg, Baden-Württemberg, Deutschland

Ausbildung:

1991-1995 Grundschule Griesheim, Stadt Offenburg, Deutschland

1995-2004 Grimmelshausen-Gymnasium, Stadt Offenburg, Deutschland

Abitur

2005-2011

Studium der Veterinärmedizin

Veterinärmedizinische Universität Wien, Stadt Wien, Österreich

Diplom-Tierärztin/Mag.med.vet.

2011-2013 Doktorat an der Klinik für Kleintiermedizin

Vetsuisse-Fakultät, Universität Zürich, Stadt Zürich, Schweiz 